\title{
Cycle-oriented approach to building a model of production costs
}

\author{
Elena P. Polikarpova ${ }^{1 *}$ and Igor E. Mizikovskiy ${ }^{2}$ \\ ${ }^{1}$ Ryazan State Agrotechnological University named after P.A. Kostychev, 390044 Ryazan, Russia \\ ${ }^{2}$ Lobachevsky State University of Nizhny Novgorod, 603950 Nizhny Novgorod, Russia
}

\begin{abstract}
Modern science and practice does not have a sufficient set of cost management tools, taking into account the duration of the production cycle, characteristic of agricultural activity. The implementation of a cycle-oriented approach to building a model of production costs was based on studying the existing options for classifying production costs, which were supplemented with features from the perspective of managing long production cycles. As a result of the study, a model of production costs was built from the point of view of a cycle-oriented approach, as well as a model of production costs from the standpoint of features of a long production cycle. The model can serve as the basis for the formation of the information space of cost management, control and cost analysis in the economy of agricultural enterprises.
\end{abstract}

\section{Introduction}

Many authors consider natural conditions of agricultural activity as one of the fundamental factors affecting the implementation of management functions, considering the unique risks and restrictions of the work of organizations that determine peculiarities of the development of the agrarian economy [1-3].

According to Zeki Doğan et al. (2013), certain expenses of agricultural enterprises relate to the budget of the next month or even the next year. In other words, the sales revenue from the production process, which presupposes certain costs, may relate to the following terms or years (for example, costs associated with the use of fertilizers, pollination of plants, etc.) [4].

However, modern science and practice do not have a sufficient set of cost management tools, taking into account the typical production cycle duration for agricultural activities.

Modeling production costs in the system of management of the enterprise involves the construction of the scheme, reflecting their characteristics and features of the formation. The cost model is based on their classification.

\section{Methods}

Production costs form the cost of labor products. The development of cost models is focused on evaluation according to processes, phases and operations of production. The parametric hybrid cost model is activitybased which means that the cost of each manufacturing operation is calculated and then summed up so that the true пер-hour factory cost rate as well as the exact unit cost (i.e. manufacturing cost) of an unlimited number of different components can be estimated [5].
The cost-estimation model for job shops classifies all activities in such shops into machine based production, labor-intensive production, technical services and administrative services [6].

When building a classification of costs, the degree of their relationship with the products manufactured and directly with the production process is considered paramount [7-13].

Thus, the division of costs into basic and overhead according to their economic role (or the technical and economic content of the production process) is widespread).

Classification criterion according to the method of including costs in the cost of production also provides for determining the cost orientation to produce a specific or several types of products, dividing them into direct and indirect (conditionally distributed).

Calculation items, detailing direct and indirect costs included in the cost of production are also treated as classification criteria. Grouping by calculation items makes it possible to determine the production cost elements for a specific type of product (work or service), which corresponds to another classification criterion by cost element.

In this case, the costs are divided into single-element and complex, depending on whether they can be divided into the corresponding components.

According to expediency of expenditure or evaluation of management activity, they allocate productive and non-productive costs, considering them from the point of view of benefits for achieving production efficiency.

In conjunction with the production process, costs are considered according to most other classification criteria: depending on the volume of production, the sphere of circulation of assets, places of origin, the sphere of

* Corresponding author: dikusar85@mail.ru 
responsibility, the scope of planning, rationing, making management decisions, etc.

There are also cost classification options that take into account time points (Table 1) [7, 8, 11, 12].

Table 1. Setting Word's margins.

\begin{tabular}{|l|l|}
\hline \multicolumn{1}{|c|}{ Classification feature } & \multicolumn{1}{c|}{ Classification elements } \\
\hline $\begin{array}{l}\text { The relation to the } \\
\text { reporting period (or in } \\
\text { accordance with the } \\
\text { assumption of time } \\
\text { certainty of the facts of } \\
\text { economic life) }\end{array}$ & $\begin{array}{l}\text { Costs of the past reporting } \\
\text { period } \\
\text { Costs for the current reporting } \\
\text { period } \\
\text { Costs of future reporting periods } \\
\text { (costs deferred in time) }\end{array}$ \\
\hline $\begin{array}{l}\text { Finishing of the } \\
\text { production cycle }\end{array}$ & $\begin{array}{l}\text { Costs related to finished } \\
\text { products } \\
\text { Costs for semi-finished articles } \\
\text { Costs in work in progress }\end{array}$ \\
\hline Time of validity & $\begin{array}{l}\text { Costs for a single production } \\
\text { cycle } \\
\text { Costs for multiple production } \\
\text { cycles }\end{array}$ \\
\hline $\begin{array}{l}\text { Depending on the } \\
\text { capitalization or } \\
\text { allocation of the reporting } \\
\text { period to the profit (by the } \\
\text { method of influence on } \\
\text { the financial result of the } \\
\text { enterprise) }\end{array}$ & $\begin{array}{l}\text { Product costs (Input costs) } \\
\text { periodic or expired (costs per }\end{array}$ \\
\hline $\begin{array}{l}\text { By stages of the product } \\
\text { life cycle }\end{array}$ & $\begin{array}{l}\text { Costs of pre-production, } \\
\text { production and post-production } \\
\text { stages }\end{array}$ \\
\hline $\begin{array}{l}\text { Depending on the } \\
\text { frequency of formation in } \\
\text { production }\end{array}$ & Current (daily) and one-time \\
\hline $\begin{array}{l}\text { Attitude to the formation } \\
\text { of cost }\end{array}$ & $\begin{array}{l}\text { Work in progress costs } \\
\text { Costs of finished products }\end{array}$ \\
\hline
\end{tabular}

It should be noted that the existing cost classification focuses on the reporting period, or considers the production cycle in conjunction with the reporting period from the point of view of cost formation in the work in progress. Obviously, the reporting period and the production cycle do not assume the same length of time. Therefore, the definition of incomplete production is used, because at the end of the reporting period the production cycle was not completed. The reporting period is generally recognized as a month or a year, after which the cost of production is calculated.

\section{Model and results}

Effective management implies a desire for maximum accuracy and efficiency in making management decisions. Therefore, planning, accounting, analysis and control of costs and production costs should focus on the period corresponding to the production cycle. The most accurate calculation of the cost of production should be ensured immediately after the completion of the product creation with a clear justification of its relationship with the orientation of costs included in the calculation. This approach has the greatest significance for long production cycles, such as crop production. For example, according to Alborov and Hosiev, at the level of self- supporting units, the objects of planning and cost accounting are separate production cycles and production phases, and calculation objects are types of work and products [7].

The recommended cycle-oriented approach to building a model of costs policy requires a review of their classification options, taking into account time guidelines. Among available characteristics (Table 1), the following ones can be applied: according to the period of validity, according to the stages of the product life cycle and depending on the frequency of formation in production.

The first feature involves consideration of costs in terms of their return (that is, production) for one or several production cycles. Examples of the cost of one production cycle are the use of raw materials for a single production of a specific product (brick for building a house, lumber for making a table, whole milk for making a batch of cream), or workers using piece-rate pay. The costs of several production cycles are the use of seeds for planting perennial crops or labor of the head of furniture production according to the time-based payment system (salary).

The criterion of classification "by stages of the product life cycle" allows to take into account the costs that form the cost of production and are accordingly immanently related to the production cycle, but actually formed before it starts (the costs of the pre-production stage), directly during the production cycle (costs of the production stage) or after it (post-production costs). According to the interpretation of the term, the product life cycle includes the period from the need for its creation to its liquidation as a result of exhaustion of consumer demand (going through the stages of design, production, operation and disposal). Therefore, from the point of view of costing, such a definition of the considered classification criterion as "according to the stages of the value stream" is seen as the most objective for internal needs of the organization.

In agricultural production, examples of preproduction costs are the costs of preparing the soil in the fall for planting a crop in spring, as well as the labor costs of planning the relevant production processes. Starting from sowing and up to harvesting and finalizing the harvest inclusive, the costs relate to the production stage. The costs of the post-production stage can be directed, for example, to provide conditions for the storage of finished products, as well as to repair fixed assets, the need for which arises as a result of their operation during the production cycle.

Depending on the frequency of costs formation, the actual consumption of resources in production is considered. Daily use throughout the entire manufacturing cycle, objects and means of labor involves the formation of current costs. Examples of one-time costs include repairs of fixed assets and onetime (annual) payments to employees. However, ultimately, the classification by the considered criterion is also focused on the distribution of costs over calendar periods: current expenditures include costs occurring in each production cycle or having some frequency (less than a month), non-recurrent expenditures - one-time or 
periodical (with a frequency of more than a month) costs. At the same time, current costs provide for the current activities of the organization, and one-time production processes for a long time.

From the point of view of the cycle-oriented approach, this cost division is correctly applicable to non-durable production cycles (several hours or days) carried out within one calendar month. Adequate accounting, when determining the cost of production, makes possible to distribute the costs of production over calendar periods so that the part of the costs included in the cost of each period corresponds to the volume of products produced in this period.

If the production cycle includes several calendar periods - months or years, then the current costs can become one-time. For example, the cost of planting to grow crops is carried out once a year, but is related to the production cycle of several months, which can occur in two calendar years (for winter crops). Labor costs for production workers also initially have a current character. However, in separate periods for a certain number of days, which may fall on two different calendar months (for example, when harvest), the actual consumption of these labor resources greatly increases and takes a one-time character already during the production cycle.

As a result of studying the existing options for the classification of production costs, it was established that it is necessary to clarify it by complementing the characteristics that correspond to the cycle-oriented approach from the standpoint of managing long production cycles.

First of all, it is proposed to classify costs depending on the duration of the production cycle: the costs of the production cycle (carried out within one reporting period) included in the reporting period (month or year) and the costs of the production cycle including multiple reporting periods (months or years). The classification criterion implies the need to establish a priority parameter - a specific reporting period, since the production cycle may include several months and be carried out within a year (for example, the cycle of growing spring crops). Current accounting of production costs in this case is carried out within a cycle that includes many months.

It should be noted that the production cycle included in the reporting period (month) often has a recurring nature of implementation during the period (for example, the cycle of kefir production). In turn, the cycle of growing spring crops is carried out once a calendar year. These examples necessitate the identification of another classification criterion. According to the repetition of the production cycle of one type of product during the reporting period, one can single out the costs of the production cycle with a consistently repeated pattern of implementation during the reporting period, the costs of the production cycle with inconsistently recurring nature of implementation during the reporting period and the costs of the production cycle once carried out.

In addition, the costs of a long production cycle (including several months or years) should be classified according to its indivisibility in the costs of an indivisible (integral) production cycle and a cycle with the possibility of differentiation. The first group is due to the natural features of production, for example, agricultural products, since the process of growing a crop or offspring (its development during the cow's pregnancy period) is irreversible, it cannot be suspended for a while, partially transferred, etc. In turn, the production cycle of a building process can be differentiated or suspended, which will increase the deadlines for the work, but this does not exclude the possibility of achieving the result of the costs in the form of completed construction.

Returning to the classification of costs by the period of action, one should consider the behavior of costs according to both differences in production cycles and differences in the results of one production cycle.

It is necessary to note the features of some production cycles in which the moment of initial consumption of raw materials is the same, but then several periods follow, ending with different points in the output of finished products of the same type. In this case, it is necessary to isolate the costs of several consecutive production cycles of the same type. An example is growing perennial crops.

There are also cases of the implementation of several cycles of production of different types, associated with each other. For example, the production of milk and offspring in dairy cattle breeding. The direct costs of production in this case are often subject to distribution among its types.

However, as a result of one production cycle, it is possible to obtain several types of related products. For example, the production of feed crops or corn. Production costs are subject to distribution between its types.

The considered features of the production cycles imply a corresponding division of costs, useful for managerial needs.

In addition, for almost every element, article, or any group of costs, costs can be objectively distinguished with a characteristic temporal uneven formation. The actual consumption of resources in the main volume falls at a certain moment (interval) of one or several production cycles, whereas the causality and expediency of these costs are not one-time in nature and reveal the need for them over a long period. Examples of costs, the implementation of which is due to ensuring the business activity of an organization over a long period before or after the actual consumption of business assets can be costs that are included in the lump sum according to the classification criterion "depending on the frequency of formation in production":

- land remediation;

- repairs of fixed assets;

- vacation pay and stimulating lump sum to employees;

- loss recovery within the norms of natural losses, production defects;

- vaccination of animals;

- warranty repair and warranty service;

- payments for pollutant emissions;

- advertising; 
- training and retraining, etc.

Other examples are uneven costs of a long-term value stream of an indivisible production cycle. These include almost all direct costs of growing grain crops. Their unevenness is due to the non-rhythmic implementation of agricultural work (production phases) for seed preparation and sowing, tillage, fertilization, snow retention, plant protection, planting care, harvesting, transportation and refining. In this case, the costs of a particular type of work cannot be attributed to a separate independent period of production, as it is advisable to provide the entire production cycle of growing crops.

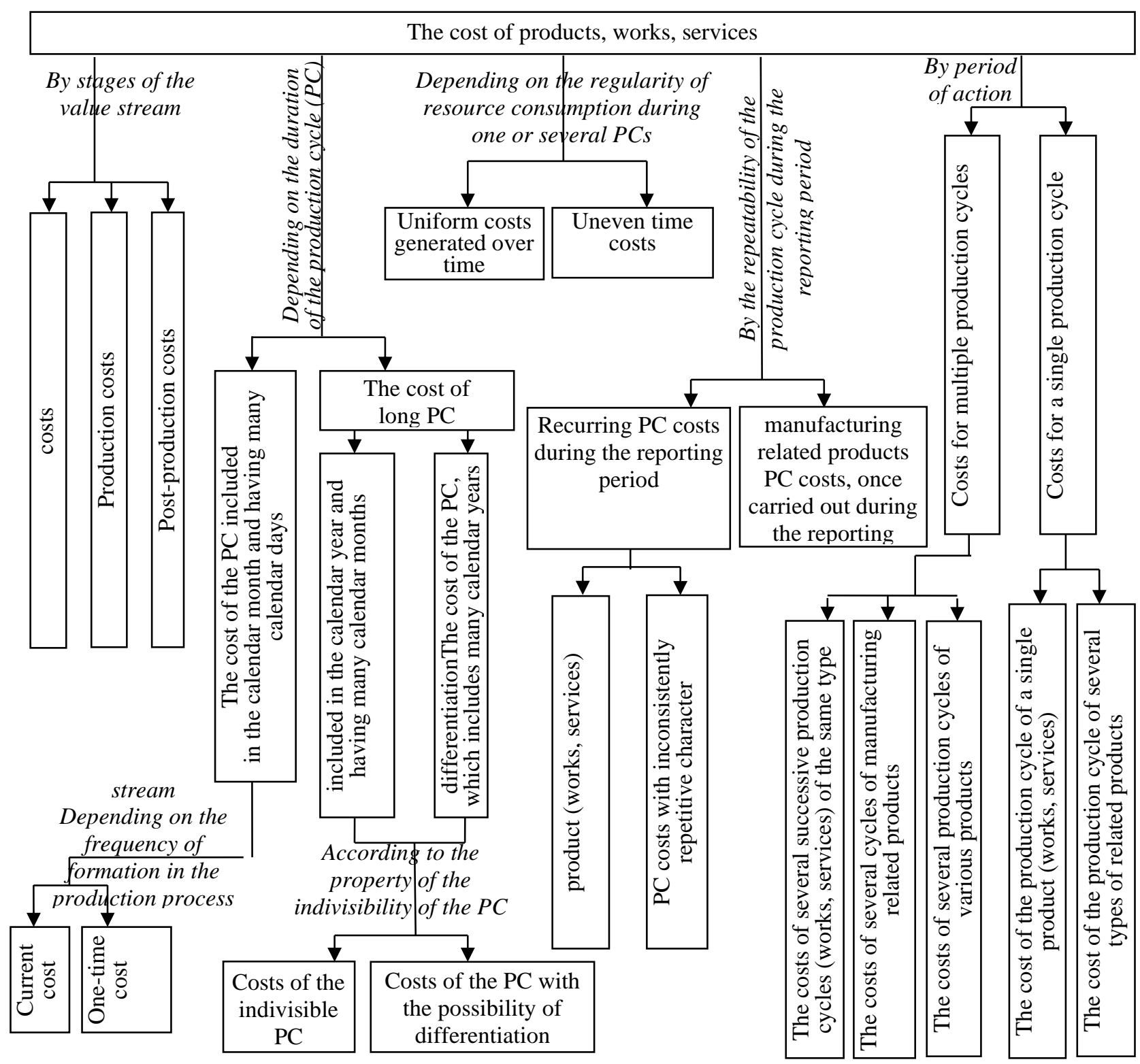

Fig. 1. Model of production costs from the point of view of the cycle-oriented approach.

\section{Conclusion}

The considered generalizing characteristic of costs makes possible to form the principle of grouping depending on the regularity of resource consumption during one or several production cycles: costs uniformly formed over time and uneven costs.

At the same time, among uneven costs we will single out the costs actually incurred during the production cycle and the costs actually incurred outside the corresponding production cycle. It should be noted that non-uniformly generated in time costs are the object of redundancy, which is an important management tool in ensuring sustainable performance of organizations [13].

As a result of the study using the methods of facet and hierarchical classification, a model of production costs was built from the point of view of a cycle-oriented approach (Fig. 1), as well as a model of production costs from the point of view of features of a long production cycle (Fig. 2). They can serve as the basis for the formation of the information space of cost management, control and analysis of costs in business entities engaged in long production cycles. 


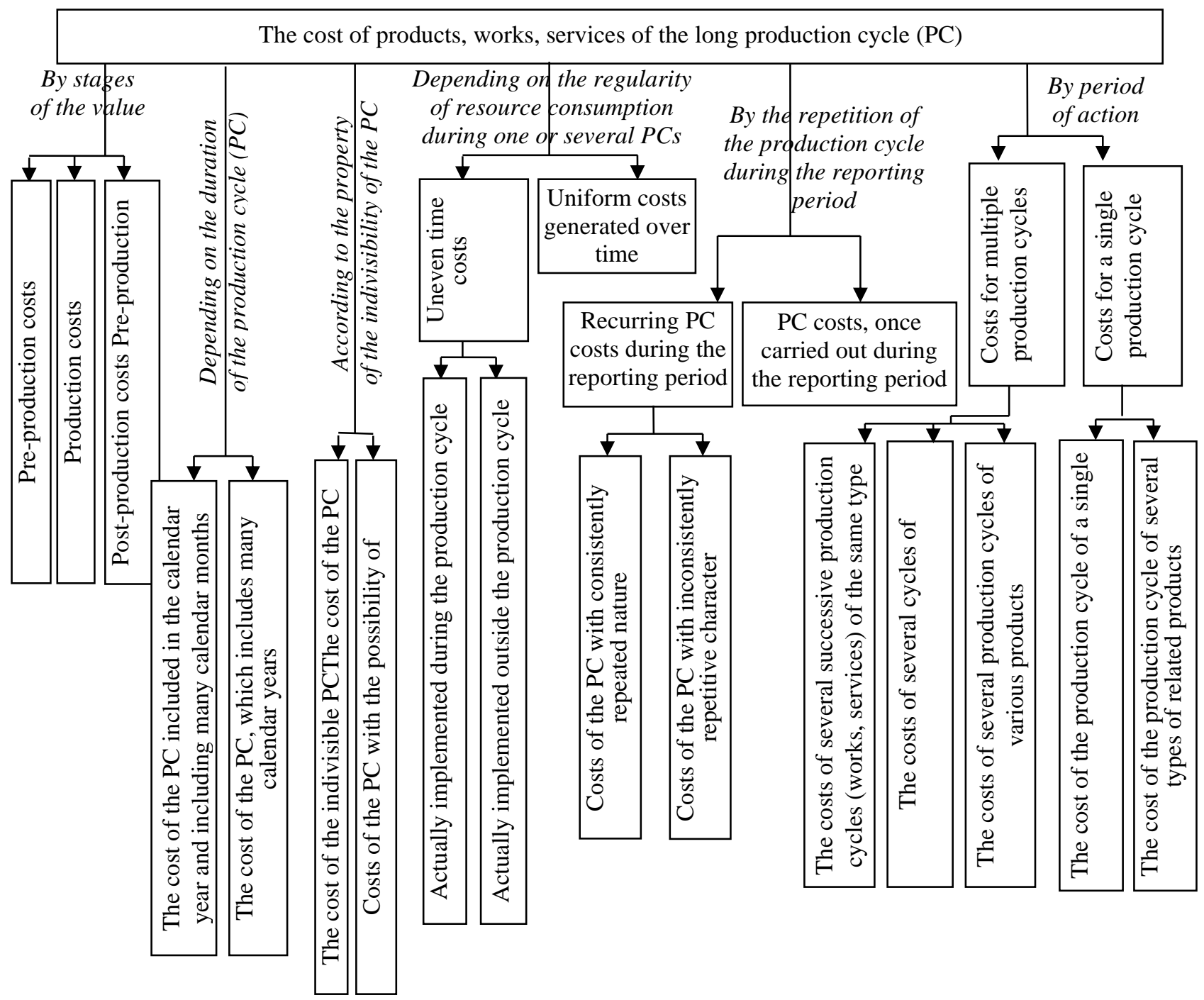

Fig. 2. Model of production costs from the point of view of features of a long production cycle.

\section{References}

1. C. Balzan, R.M. Dallágnil, Custos e @gronegócio on line 13(4), 17-41 (2017)

2. M.M.B. Brizolla, T.T. Chiarello, C.S. Pletsch, L.B. Fasolin, A. Da Silva, Custos e @gronegócio on line 13(4), 257-282 (2017)

3. N.C. De Oliveira, A.C.C. Baqueta, M. Neumann, R.R.M. Ribeiro, K. Mattielo, Custos e @gronegócio on line 14(3), 37-60 (2018)

4. Zeki Doğan, Seçkin Arslan, Ayșe Gül Köksal, Int. J. of Food and Agricult. Econ. 1(2), 105-114 (2013)

5. S. Langmaak, S. Wiseall, C. Bru, R. Adkins, J. Scanlan, A. Sóbester, Int. J. of Product. Econ. 142(1), 74-88 (2013)

6. A. Aderoba, Int. J. of Product. Econ. 53(3), 257-263 (1997)
7. R.A. Alborov, B.N. Hosiev, Proceedings of Gorsky SAU 50(3), 213-218 (2013)

8. A.R. Zakirova, Innovat. Development of Econ. 4, 74-78 (2011)

9. E.A. Mizikovsky, I.E. Mizikovsky, E.P. Polikarpova, Accounting of reserves (Publishing House of RSATU, Ryazan, 2017)

10. T.A. Miroshnichenko, N.N. Korogod, Vestnik of Don State Agrar. Univer. 3-1(25), 73-82 (2017)

11. Z.S. Tujakova, G.B. Sarsembayeva, Intellect. Innovations. Investments 37-43 (2018)

12. E.S. Shupletsova, G.Y. Butorina, Int. sci.-pract. Conf. Modern science to agro-industrial production 91-94 (2014)

13. E.P. Polikarpova, I.E. Mizikovskiy, Custos e @gronegócio on line 14(4), 149-165 (2018) 